DOI: https://doi.org/10.24867/050I04Kalin

\title{
ANALIZA ZASTUPLJENOSTI I PROCENA PERFORMANSI VEB TEHNOLOGIJA U OBLASTI ŠKOLSTVA REPUBLIKE SRBIJE
}

\section{ANALYSIS OF FREQUENCY OF USE AND PERFORMANCE OF WEB TECHNOLOGIES IN THE EDUCATION AREA OF REPUBLIC SERBIA}

\author{
Igor Kalin, Fakultet tehničkih nauka, Novi Sad
}

\section{Oblast - Informaciono-komunikacioni sistemi}

Kratak sadržaj - U ovom radu sprovedena je analiza zastupljenosti različitih veb tehnologija u izradi pedeset veb sajtova $u$ oblasti školstva na teritoriji Republike Srbije. Nakon toga, izvršena je analiza performansi najzastupljenijih CMS sistema uočenih u sprovedenom istraživanju. Kao krajnji rezultat, doneta je odluka o odabiru tehnologije za unapređenje sajta škole „Milan Petrovic' " u Novom Sadu.

Ključne reči: Veb tehnologije, CMS, WordPress, Joomla, Drupal

\begin{abstract}
This paper analyzes the representation of various web technologies in the development of fifty websites in the field of education in the territory of the Republic Serbia. Subsequently, the performance analysis of the most common CMS systems observed in the conducted research was performed. As a result, a decision to select the technology for upgrading the site of the ,Milan Petrovic“ School in Novi Sad was made.
\end{abstract}

Keywords: Web technologies, CMS, WordPress, Joomla, Drupal

\section{UVOD}

U današnje vreme, CMS (Content Management System), odnosno, sistemi za upravljanje sadržajem otvorenog kôda, preuzeli su primat na tržištu veb razvoja. Njihova primena najčešće se ogleda u razvoju veb sajtova čija je primarna svrha omogućavanje kreiranja vizuelno privlačnih, kontekstno bogatih stranica na veb-u, a povrh svega i mogućnost samostalnog održavanja tih stranica od strane krajnjih korisnika. Potreba za održavanjem dobrog sadržaja na sajtu znači njegovo stalno revidiranje, objavljivanje, ažuriranje i upravljanje njime na zanimljiv i jednostavan način.

Održavanje većih veb stranica je ogroman zadatak koji teško može biti izvodljiv bez korištenja sistema za upravljanje sadržajem (CMS). Tokom godina, razvijano je mnogo različitih vrsta CMS sistema. Trenutno se procenjuje da ih ima između 250 i 350 dostupnih na tržištu. Od tolikog broja aktivnih sistema ovog tipa, tek oko 20 je doživelo značajniju primenu vrednu dublje analize i komparacije sa ostalim.

\section{NAPOMENA:}

Ovaj rad proistekao je iz master rada čiji mentor je bio dr Darko Stefanović, vanr. prof.
Mnogi od njih nisu doživeli očekivanu ekspanziju i stepen prihvatljivosti od strane korisnika. U njih spadaju sistemi kao što su Weebly, Brix, PrestaShop, Magento, Shopify, TYPO3, ali i mnogi drugi. Sa druge strane, određeni CMS sistemi su preuzeli veliku ulogu u razvoju vebu, ali i promociji ovakve vrste načina upravljanja sadržajem na vebu. U takve sisteme spadaju WordPress, Joomla i Drupal, kao najpoznatiji predstavnici CMS sistema na vebu [1].

$\mathrm{U}$ ovom radu, u okviru poglavlja 2, predstavljena je metodologija sprovedenog istraživanja, a zatim u okviru poglavlja 3 predstavljeni su rezultati izvršenog istraživanja korišćenih veb tehnologija u izradi pedeset sajtova srednjih škola na područje Srbije u okviru četiri najveća grada (Beograd, Novi Sad, Kragujevac i Niš), a zatim je, u poglavlju 4, dat pregled poređenja performansi tri, prethodno navedena, sistema uz dodatnu diskusiju dobijenih rezultata.

Kao krajnji rezultat, doneta je odluka o odabiru tehnologije za izradu novog, zvaničnog sajta škole za osnovno i srednje obrazovanje "Milan Petrović", u Novom Sadu. Potreba za izradom sajta škole „Milan Petrović" proistekla je na osnovu prethodno obavljenje analize tržišnih potreba i zahteva korisnika trenutnog sajta za unapređenjem njegovog dizajna i strukture.

\section{METOD ISTRAŽIVANJA}

Prikupljanje podataka vršeno je na osnovu javnog uvida $u$ zvaničan spisak srednjih škola u Republici Srbiji. Nakon kreiranja inicijalnog uzorka, Google pretragom vršena je provera trenutne, aktivne verzije školskog veb sajta. Analiza tehnologija vršena je pomoću besplatnog internet alata pod nazivom Wappalyzer. Uzorak od 50 sajtova $\mathrm{i}$ njihovih tehnologija sačinjen je analizom sajtova najvećih srednjih škola u okviru 4 najveća grada u Srbiji. To su Beograd, Novi Sad, Kragujevac i Niš.

Najveći uzorci od po 15 sajtova srednjih škola odabrani su, najpre, za najveći grad - Beograd, pri čemu je nasumično odabrana po jedna srednja škola iz po jedne opštine u tom gradu, a zatim i Novi Sad kao sedište škole čija je izrada sajta i predmet ovog rada. Iz ostalih gradova (Niš i Kragujevac), odabrano je po 10 referentnih škola kako bi ovaj uzorak bio što reprezentativniji. 


\section{REZULTATI ISTRAŽIVANJA}

Prilikom evidencije tehnologije svakog sajta, pored alata, programskog jezika ili sistema u kojem je on urađen, posebno je navedeno da li je data tehnologija CMS ili nije. Ovaj podatak može biti od velikom značaja prilikom odabira konačne tehnologije za izradu sajtu, jer otkriva načine za upravljanjem samom sadržinom sajta od strane većine korisnike iz posmatrane oblasti. Grafikon prikazan na slici 1 , svedoči u prilog tome da se čak $80 \%$ škola iz posmatranog uzorka opredelilo za neku od CMS tehnologija pri izradi svog sajta.

U ostalih $20 \%$ spadaju neki od najpopularnijih veb alata za izradu, kako statičkih, tako i dinamičkih internet stranica. Ipak, njihova zastupljenost u ovom slučaju ograničena je na svega $20 \%$ srednjih škola u Srbiji, što predstavlja izrazito nizak procenat, obzirom na generalnu zastupljenost tih tehnologija na samom veb-u.

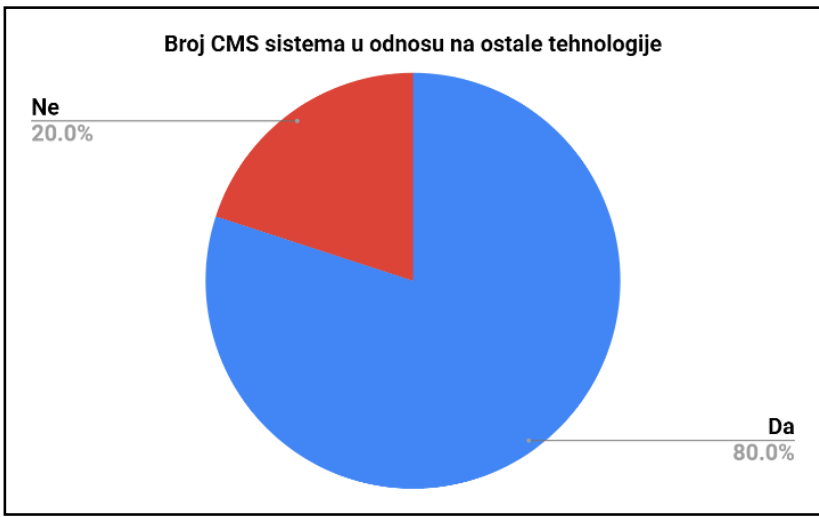

Slika 1. Procentualni prikaz zastupljenosti CMS sistema u odnosu na druge tehnologije

Grafikon na slici 2, prikazuje histogram raspodele najzastupljenijih tehnologija u datom uzorku. $\mathrm{Na}$ osnovu dobijenih rezultata, primećujemo da je daleko najzastupljenija tehnologija WordPress CMS sistem, koji se u ovom uzorku pojavljuje kao primarna tehnologija u čak 30 od ukupno 50 obrađenih sajtova. Nakon toga sledi Joomla, koja svoju primenu pronalazi u ukupno 8 sajtova iz ovog uzorka.

Pet sajtova u datom primeru, rađeno korišćenjem iskučivo HTML-a (HyperText Markup Language), i CSS-a (Cascade Style Sheets), kao alata za izradu klijentskog dela aplikacije, bez odgovarajućeg serverskog dela u pozadini. Pored ovih alata, tu spadaju i dodatne CSS i JavaScript biblioteke poput Boostrap-a illi jQuery-ja.

Četiri sajta iz uzorka, pored klijentskog dela aplikacije koji je rađen pomoću nekog od prethodno pomenutih alata, ima serverski deo zasnovan na čistom PHP (Hypertext Preprocessor) jeziku, ili nekom njegovom framework-u poput Laravel-a.

Ovo omogućava kreiranje dodatnih funkcionalnosti kao i pravljenje posebnih administratorskih panela pomoću kojih će korisnik, samostalno moći da menja sadržaj na samom sajtu, ali ne i njegov dizajn i strukturu, što nam omogućavaju standardni CMS sistemi.

Takođe, po jednom sajtu iz uzorka detektovane su još dve tehnologije CMS sistema poput Drupal-a i Weebly-ja, kao i jedna tehnologija zasnovana na $C \#$ programskom jeziku, a to je ASP.NET Framework za izradu veb aplikacija.

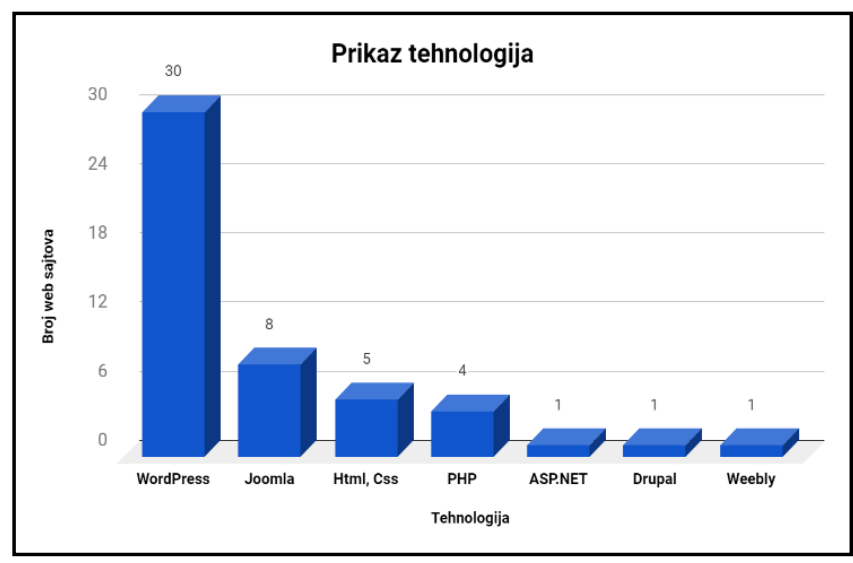

Slika 2. Histogram zastupljenosti različitih veb tehnologija u odnosu na broj analiziranih sajtova

Pregledom procenutalne raspodele dobijenih rezultata, na slici 3, moguće je primetiti da WordPress zauzima $60 \%$ ukupno detektovanih tehnologija školskih sajtova u Srbiji. Sledi ga Joomla sa $16 \%$, dok ostalih pet uočenih tehnologija zauzima preostalih $22 \%$ pregledanih rezultata. Ako se u obzir uzme i činjenica da WordPress zauzima oko $27 \%$ veba, ovakvi rezultati su potpuno opravdani i očekivani, posebno razmatrajući i obrazovnu oblast iz koje je ovaj uzorak i sačinjen.

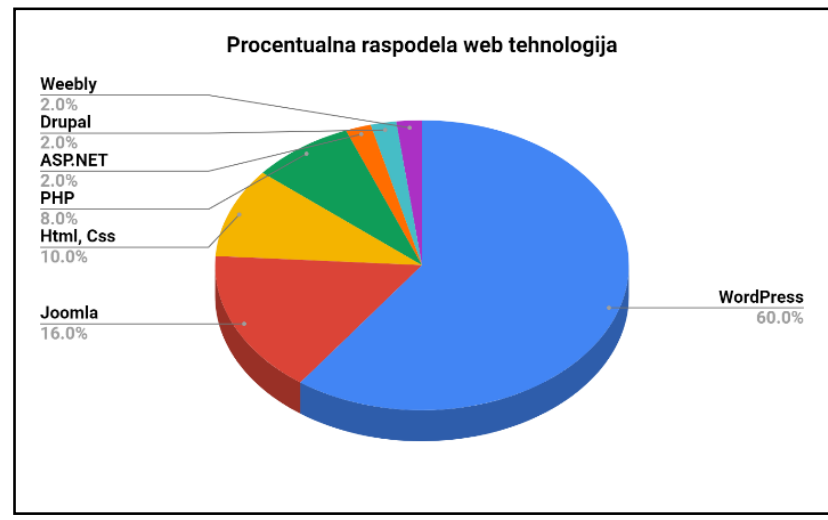

Slika 3. Prikaz procentualne raspodele zastupljenih veb tehnologija

$\mathrm{Na}$ osnovu prikazanih statističkih podataka, moguće je zaključiti da se daleko najveći broj srednjih škola u Srbiji odlučuje za neku od CMS tehnologija pri izradi i upravljanju svojim školskim sajtovima. Ovakav rezultat potvrđuje pretpostavku da su takvi sistemi najoptimalniji kada je u pitanju ovakva sfera poslovanja, te da bi i u izradi sajta škole „Milan Petrović” u Novom Sadu, koji je i tema ovog rada, neka od prikazanih CMS tehnologija doprinela najsigurnijem ispunjenju, kako sadašnjih, tako i budućih korisničkih zahteva. Posmatranjem zastupljenih CMS-ova iz ovog primera, potrebno je doneti odluku o najboljem od njih. WordPress predstavlja ubedljivo najzastupljeniju veb tehnologiju u oblasti obrazovanja, posmatravši manji uzorak srednjih škola na teritoriji Srbije. Takođe, njegov udeo u okviru zastupljenih CMS sistema iz posmatranog uzorka je daleko najveći. Prati ga Joomla u nešto manjem procentu, ali i Drupal i Weebly čije je procentualno učešćenje u ovom uzorku minimalno ali bi ipak trebalo biti uzeti u razmatranje pri odabiru 
najbolje tehnologije za izradu sajta. Kako bi se odluka o izboru najboljeg CMS sistema od ponuđenih, donela na pravi način, potrebno je koristiti određene empirijske podatke o njihovom kvalitetu. U nastavku ovog rada, u okviru poglavlja 4, sledi analiziranje osnovnih performansi tri glavna CMS sistema u koje spadaju WordPress, Joomla i Drupal, a nakon toga i diskusija dobijenih rezultata.

\section{ANALIZA PERFORMANSI I DISKUSIJA REZULTATA}

Osvajanjem tržišta, Open-Source CMS sistemi postali su veoma rasprostranjeni i kao sistemi otvorenog kôda, veoma brzo su počeli da se pojavljuju u velikom broju različitih vrsta i formi. Iako nijedan sistem nije najbolji za sve, vremenom su se iskristalisala tri glavna predstavnika u ovoj oblasti, a to su: WordPress, Joomla i Drupal. U nastavku, sledi prikaz glavnih performansi ova tri sistema na osnovu kojih se može doći do zaključka koji od njih ima manju, ili veću prednost nad ostalim. U istraživanju iz 2010. godine, sprovedenom od strane profesora Gangat Univerziteta u Indiji izvršeno je poređenje performansi na osnovu jedne iste stranice u tri različita CMS sistema [2]. Kreirana je statistika stranice koja sadrži samo tekstualne informacije, stranice sa jednim objektom, a zatim sa više objekata kao što su kalendar, sat i galerija slika, a sve u cilju provere toga koji CMS bolje upravlja i daje brži odgovor. Kalendar, sat i galerija ubačeni su pomoću specijalnih plugin-ova. Pregled korišćenih verzija i plugin-ova, dat je u tabeli 1.

\begin{tabular}{|l|l|l|l|l|}
\hline CMS & Verzija & Kalendar & Sat & Galerija \\
\hline Joomla & 1.6 .4 & Minicalendar & Jtime & Simplespot \\
\hline Drupal & 6 & $\begin{array}{l}\text { Calendar } \\
\text { Block }\end{array}$ & $\begin{array}{l}\text { Time } \\
\text { Block }\end{array}$ & CyclePlugin \\
\hline WordPress & 3.1 .3 & In Built & $\begin{array}{l}\text { Local } \\
\text { Clock }\end{array}$ & $\begin{array}{l}\text { JS Banner } \\
\text { Rotate }\end{array}$ \\
\hline
\end{tabular}

Tabela 1 - Pregled korišćenih plugin-ova

Nakon kreiranja stranica u sva tri različita sistema, kreirane su dve studije slučaja putem kojih je izvršena komparacija performansi posebno na lokalnom serveru, a posebno na live serveru.

\subsection{Testiranje na lokalnom serveru}

Prethodno kreirane stranice u sva 3 CMS sistema, postavljeni su na lokalni server. Konfiguracija servera prikazana je u tabeli 2 .

\begin{tabular}{|l|l|}
\hline Operativni sistem & Windows XP \\
\hline Konfiguracija hardvera \\
\hline Procesor & Core 2 DUO \\
\hline RAM & 2 GB \\
\hline Hard Disk & 320 GB \\
\hline Matična Ploča & Intel Motherboard \\
\hline Server & Apache Server 2.2.19 \\
\hline Front-End tehnologija & PHP 5.0 \\
\hline Back-End tehnologija & My SQL 5.0 Server \\
\hline
\end{tabular}

Tabela 2 - Pregled konfiguracije lokalnog servera
Za merenje performansi stranice korišćeni su sledeći parametri:

- Brzina učitavanja stranice izražena u milisekundama (M.S).

- Veličina stranice u kilobajtima (K.B).

- Ukupan broj zahteva poslatih serveru do učitavanja stranice.

Dobijani rezultati su pokazali da, na lokalnom serveru, osim brzine učitavanja stranice nakon keširanja, Joomla ima najviše vrednosti u poređenju sa WordPress-om i Drupal-om, što ga čini najsporijim po svim prikazanim parametrima. Kada je reč o čistom učitavanju stranice prvi put, Drupal se pokazao kao najbrži sa brzinom učitavanja od $520 \mathrm{~ms}$. To je zato što on, pri svom učitavanju, koristi najmanji broj JS (JavaScript) fajlova. WordPress-u je bilo potrebno čak 4 puta više vremena nego Joomla-i i 7 puta više vremena nego Drupal-u, ali se pokazalo da prilikom prvog učitavanja kešira značajnu količinu podataka, čime se brzina učitavanja stranice znatno povećava prilikom narednog učitavanja. Ostali testovi pokazali su da se na lokalnom serveru Joomla ponaša najbolje. Brzina učitavanja stranica pokazala se kao najniža kod ovog CMS sistema. Međutim, rezultati lokalnog i live servera često su kontradiktorni [2]. U nastavku sledi prikaz rezultata merenja performansi na live serveru.

\subsection{Testiranje na live serveru}

U ovom primeru, CMS stranice su postavljene na live server i zahtevi ka njima su slati sa klijentske mašine. Svi prethodni parametri u ovom slučaju su uzeti $u$ razmatranje. U ovom slučaju, brzina učitavanja zavisiće od konfiguracije servera, konfiguracije klijentske mašine ali i brzine internet protoka kojom se taj zahtev šalje. Konfiguracije klijentske i serverske mašine su prikazane ispod:

- Konfiguracija servera:

1. Operativni sistem: Linux

2. Arhitektura: $x 86 \_64$

3. Kernel Verzija: 2.6. 18-238.12.1.eI5

4. Prostor na hard disku: Neograničen

- Konfiguracija klijenta:

1. OS - Win XP

2. RAM - 1 GB

3. Internet konekcija- Broadband $2 \mathrm{MB}$

4. Processor - Dual Core

5. Hard Disk - 320 GB

$\mathrm{Na}$ slici 4, prikazani su rezultati brzine učitavanja različitih vrsta kreiranih stranica. Prilikom učitavanja stranica koje u sebi sadrže samo tekstualne informacije, Joomla i Drupal prikazuju gotovo istu brzinu, dok je WordPress skoro dupli brži od svojih konkurenata, tj. vreme učitavanja te stranice u ovom CMS-u kraće je za 1.9 sekundi. Dodavanjem objekata na stranicu, vreme učitavanja se povećalo za sve ali je WordPress i dalje ostao u prednosti što se tiče brzine. 


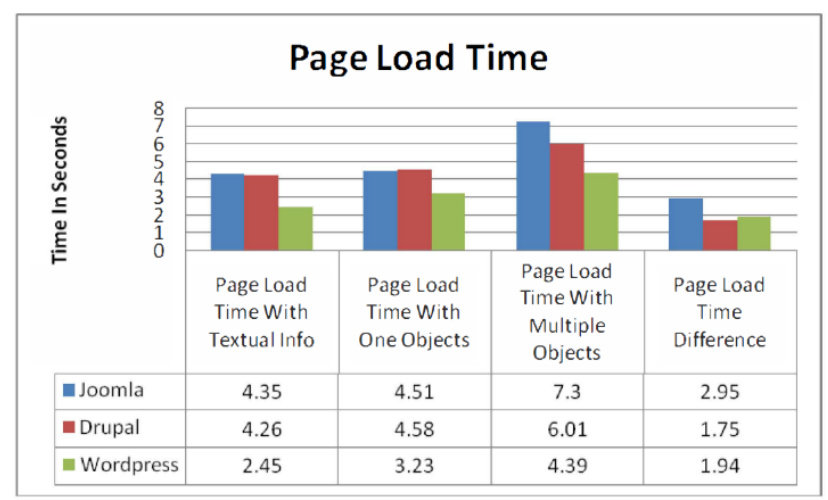

Slika 4. Poređenje brzina učitavanja stranica

Što se tiče veličine učitane stranice, njeni rezultati su prikazani na slici 5. Kada je reč o stranicama sa tekstualnim informacijama, Joomla kreira stranice čija je veličina 10 puta veća od Drupalove. Sa druge strane WordPress ima duplo veću stranicu od Drupala. Po ovom parametru Drupal se ističe kao najoptimalniji, međutim ako pogledamo i druge dve vrste stranice primećujemo da to nije slučaj. Prilikom dodavanja plugin-ova u stranice, primeđujemo da WordPress najbolje podnosi dodatno opterećenje. U slučaju Drupala, veličina stranice se povećava za duplo. Ovakvi rezultati nameću zaključak da je u slučaju jednostavnih, statičnih stranica bolje koristiti Drupal, međutim, u slučaju kada sadržaj mora da bude obogaćen različitim funkcionalnostima $u$ okviru date stranice, WordPress bi bio najoptimalnije rešenje po pitanju uštede resursa [2].

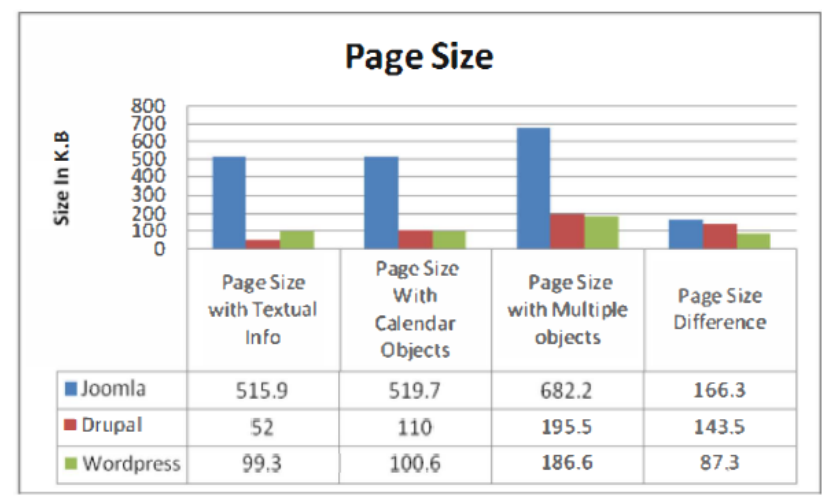

Slika 5. Poređenje veličina učitanih stranica na osnovu dodatih objekata

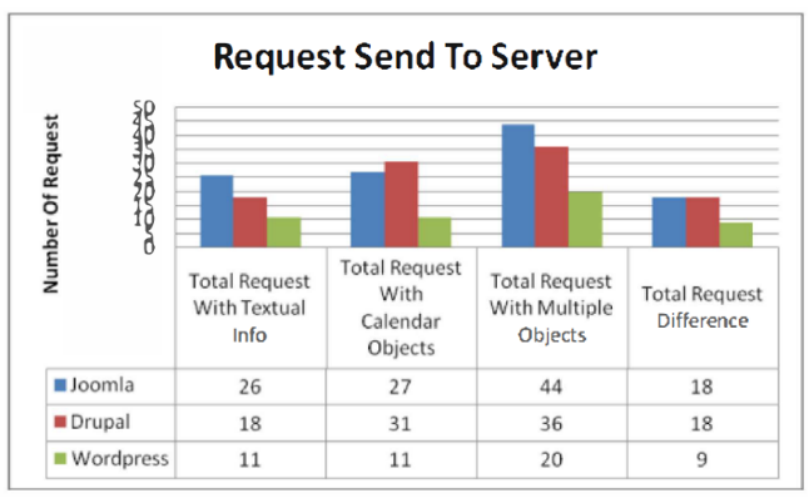

Slika 6. Poređenje broja zahteva poslatih serveru
Da bi se stranica uspešno učitala, određeni broj zahteva mora biti poslat sa klijentske ka serverskoj strani. Zahtev je u direktnoj srazmeri sa brzinom učitavanja stranice. To znači da će brzina učitavanja stranice biti veća ukoliko je ka njoj poslat manji broj zahteva. Na slici 6, vidimo da Drupal koristi 1.5 puta više zahteva od WordPress-a. Zbog manjeg broja zahteva, WordPress-u je potrebno manje vremena da učita određenu veb stranicu.

\section{ZAKLJUČAK}

$\mathrm{Na}$ osnovu prikazanih rezultata i poređenja osnovnih CMS sistema, moguće je proizvesti više različitih zaključaka. Ukoliko je cilj korisnika da poseduje sajt sa informativnim veb stranicama, koje neće sadržati nikakve posebne funkcionalnosti, Drupal bi bio najbolji izbor, s obzirom da ima najoptimalnije vreme učitavanja stranica kada je takav sadržaj u pitanju.

U drugom slučaju, ako korisnik želi da kreira intranetsku mrežu sa više stranica obogaćenim različitom vrstom funkcionalnog sadržaja, najbolji izbor u tom slučaju bi bila Joomla, jer se ispostavilo da ovaj CMS ima najoptimalnije vreme učitavanja stranica, ali samo ukoliko se sajt nalazi na lokalnom serveru.

Ipak, u najvećem broju slučajeva, potrebno je imati funkcionalni sajt, sa bogatim stranicama koje omogućavaju korisniku veću interakciju i širok spektar mogućnosti prilikom korišćenja istih. U tom slučaju, WordPress se u najvećem delu testiranja pokazao kao najbrži i najstabilniji CMS sistem, koji će prosečnom korisniku pružiti zadovoljavajuće iskustvo u pogledu performansi veb sajta.

U konkretnom primeru ovog rada, na osnovu prethodno obrađene analize performansi, ali i činjenice zastupljenosti veb tehnologija u sferi školstva na teritoriji Republike Srbije, odabran je WordPress kao CMS sistem koji će u najvećoj meri odgovoriti na korisničke zahteve datog primera, a to je unapređenje sajta škole za osnovno i srednje obrazovanje „Milan Petrovič“ u Novom Sadu.

\section{LITERATURA}

[1] R. Shreves, „Open Source CMS Market Share,“ Creative Commons Attribution-Noncommercial License, 2008.

[2] S. K. Patel, V. Rathod i S. Parikh, ,Joomla. Drupal and WordPress - A Statistical Comparison of Open Source CMS,“ u 3rd International Conference on Trendz in Information Sciences \& Computing (TISC2011), Chennai, India, 2011.

\section{Kratka biografija:}

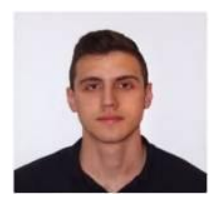

Igor Kalin rođen je u Novom Sadu 1994. god. Master rad na Fakultetu tehničkih nauka iz oblasti Inženjerstva informacionih sistema odbranio je 2019. god. Kontakt: igor.kalin@uns.ac.rs 